\title{
EVALUATION OF MATERIAL PROPERTIES OF STRUCTURAL STEELS USING ARTIFICIAL INTELIGENCE NEURAL NETWORK METHOD
}

\author{
${ }^{1}$ Ladislav KANDER, ${ }^{2}$ Petr POLCAR, ${ }^{1}$ Ondřej DORAZIL, ${ }^{1}$ Šárka STEJSKALOVÁ, ${ }^{1}$ Petr ČĺžEK \\ ${ }^{1}$ MATERIAL AND METALLURgICAL RESEARCH Ltd., Ostrava, Czech Republic, EU, \\ ladislav.kander@mmvyzkum.cz \\ ${ }^{2}$ Research and Testing Insitute Pilsen, Pilsen, Czech Republic; EU \\ polcar@vzuplzen.cz
}

https://doi.org/10.37904/metal.2019.847

\begin{abstract}
This work summarizes results and progress in new method development for identification of material properties of steel. This work deals with application of the small punch test for evaluation of material degradation of power station in the Czech Republic within the project TE01020068 "Centre of research and experimental development of reliable energy production, work package 8: Research and development of new testing methods for evaluation of material properties". The main effort is here an improvement of empirical correlation of selected steel materials used in power industry for the manufacturing of critical components (rotors, steampipes, etc.). The effort here is on the utilization of the finite element method (FEM) and the neural network (NN) for evaluation of mechanical properties (Young modulus of elasticity, yield stress, tensile strength) of the selected material, based on SPT results only. Paper contains results of experimental work carried out over past 7 years. After modification of actual neural network and increasing of the number of results interesting results of mechanical properties prediction have been obtained. Increasing data of points in common up to 300 , leads to significantly lower deviation that varies about 3-5\%.
\end{abstract}

Keywords: Small Punch Test, neural network, power plant steel, mechanical properties methods

\section{INTRODUCTION}

Currently, there is an effort to maximize the service life of nearly worn out operating components while maintaining the conditions for reliable and safety operation. Consequently, the new test methods for evaluation of residual service life or for determination of the actual strength values and brittle fracture properties of the exploited components are being developed. One of the methods used to evaluate the current state of mechanical properties is the small punch test (SPT) [1-4]. Such experimental method is used for both assessing the current condition of the material as well as evaluating the so-called zero states of newly manufactured power plants components.

This paper continues the previous work, it is main aim is to create and improve a numerical tool, which could estimate material parameters of the particular steel, on basis of already performed experiments for penetration test (SPT) and tensile test. There will not be a requirement to perform the tensile test with the currently tested material and to identify these parameters from this test. This approach can significantly reduce the time and cost of the material parameters assessment.

The standard process of identifying yield stress, tensile strength and fracture toughness is to perform tensile test and based on results of the test, the material properties can be evaluated [5,6]. However, tensile test requires large specimen of the material and it could be financially and time demanding task. The small punch test has advantage of small specimen required for the test and relatively lower cost, but it does not allow us to directly evaluate the material properties. Material properties are usually empirically correlated and type of correlation depends on laboratory, material, stiffness of tensile equipment etc. To ensure the safety operation of the component, it is necessary to find out the actual values of the material parameters based only on small 
material volume taken out and SPT. It would be sufficient to perform just a small punch test and using a suitable mathematical apparatus to identify such mechanical parameters. This newly developed approach could facilitate identification of the actual material parameters of steel in a timely and economical manner.

\section{NUMERICAL METHOD}

A neural network (NN) was chosen as a suitable mathematical apparatus. The neural network is a computational system originally inspired by nature and the human brain. Dr. Robert Hecht-Nielsen defined the neural network as follows:

"...a computing system made up of a number of simple, highly interconnected processing elements, which process information by their dynamic state response to external inputs.

In Neural Network Primer: Part I by Maureen Caudill, Al Expert, Feb. 1989. The original idea of the neural network was to solve the problems in a way that human brain would do, but over time many other applications were discovered. The main idea is that the network can be trained/taught using input and output data to give reasonable outputs for new inputs. The structure of the neural network is seen in Figure 1, where the first layer is the input; the last layer is the output and between them is (optional) number of the hidden layers. Each layer contains mutually connected nodes, and these are further connected to other nodes in the next layer. This way, we get to the last layer, i.e. to the output data. However, it is necessary to properly train the network in order to create suitable connections between the layers and the nodes. There should be several hundreds to several thousands of input/output pairs required to properly train the network.

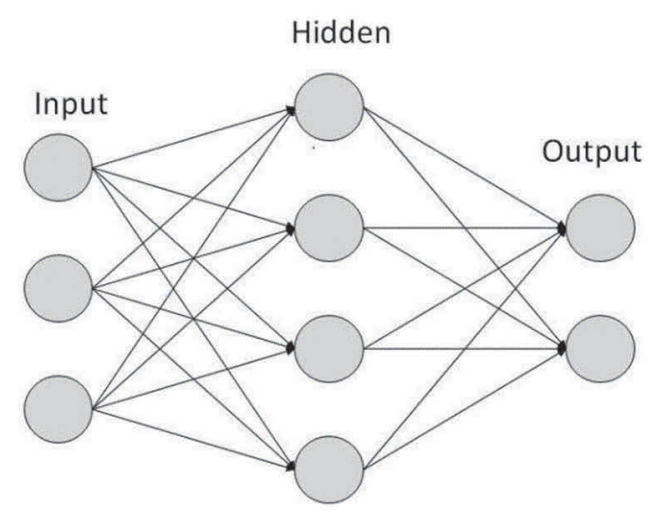

Figure 1 Structure of the neural networks

In this case, the network would have the data from the penetration test as input and one of the following material parameters as output: Young's modulus of elasticity $E$, yield stress $R_{p 02}$ and tensile strength $R_{m}$, see Figure 2. The neural network has the data from the penetration test as input (curve of Force versus Strain) and the output is always one material constant. Thus, for each material value, one single network was created.

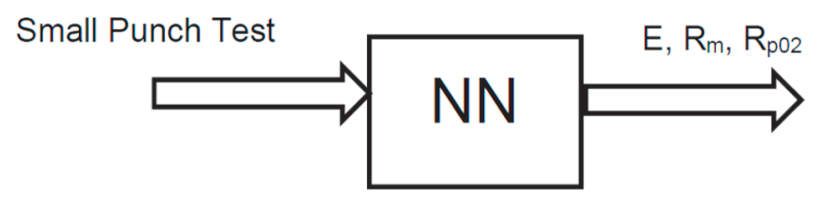

Figure 2 Diagram of the neural network based program

The neural network can be trained with the set of known data set. Here, experimental testing of SPT and tensile properties of the given material were considered. From the standard tensile test, the material parameters can be identified and directly used for the neural network training output. The input here was the 
force curve measured during SPT experiment. Consequently, the training dataset for the neural networks consist of the material parameters $\left(E, R_{p 02}\right.$ and $\left.R_{m}\right)$ as an output and SPR curve as an input. The neural network must not only be trained, it is always necessary to test it with the use of some known pair of the inputoutput, which was not used in training. Here 100 datasets were available for the 3 types of low alloyed steels used in power industry. Number of 99 pairs were used for network training and left one pair for testing. This was done gradually with all 100 values (each of this will become a testing value). The final error of the neural network prediction was then evaluated.

As an alternative all data points using slightly modified neural network were used for calculation, results and comparison have been already published in [7].

\section{EXPERIMENTAL METHODS}

Three grades of steels were used in both nuclear and classic power industry. Low alloy bainitic 10Gn2MFA steel is exploited in nuclear power engineering on a long term basis and successfully, particularly in the nuclear power engineering for power station of type VVER 1000 and MIR 1200. It was subjected to real heat treatment procedures in order to achieve real level of mechanical properties and to provide enough experimental data for the neural networks. Chemical composition can be seen in the Table 1.

Table 1 Chemical composition of 10GN2MFA grade steel [wt.\%]

\begin{tabular}{|c|c|c|c|c|c|c|c|c|c|c|}
\hline & $\mathbf{C}$ & $\mathbf{S i}$ & $\mathbf{M n}$ & $\mathbf{C r}$ & $\mathbf{N i}$ & $\mathbf{M o}$ & $\mathbf{V}$ & $\begin{array}{c}\mathbf{S} \\
\max \end{array}$ & $\begin{array}{c}\mathbf{C u} \\
\max \end{array}$ & $\begin{array}{c}\mathbf{P} \\
\max \end{array}$ \\
\hline & & $0.17-$ & $0.8-$ & & $1.8-$ & $0.4-$ & $0.03-$ & & & \\
10GN2 MFA & $0.08-0.12$ & 0.37 & 1.1 & $\max 0.3$ & 2.3 & 0.7 & 0.07 & 0. & 0.3 & 0.02 \\
\hline
\end{tabular}

Austenitic 08Ch18N10T (AISI 316) also used in nuclear power engineering was chosen as second type of steel due to different material characteristics. Well known grade of steel successfully used for parts as steam generator has chemical composition given in Table 2.

Table 2 Chemical composition of 08Ch18N10T grade steel [wt.\%]

\begin{tabular}{|c|c|c|c|c|c|c|c|c|c|}
\hline & C & Si & $\mathrm{Mn}$ & $\mathrm{Cr}$ & $\mathrm{Ni}$ & $\mathrm{Ti}$ & $S \max$ & Cu max & $\mathrm{P}$ max \\
\hline 08Ch18N10T & $\max 0.09$ & $\begin{array}{c}\max \\
0.8\end{array}$ & $\max 1.5$ & $\begin{array}{l}17.0- \\
19.0\end{array}$ & $10.0-11.5$ & $5 \times C-0.6$ & 0.02 & 0.3 & 0.035 \\
\hline
\end{tabular}

Last type of steel used in our analysis is low alloyed creep resistance steel 15128 (14MoV6-3), originally developed in our country and long-term exploited in power industry in the Czech Republic. Chemical composition is given in the Table 3 .

Table 3 Chemical composition of 14MoV6-3 grade steel [wt.\%]

\begin{tabular}{|c|c|c|c|c|c|c|c|c|}
\hline & C & Si & $\mathrm{Mn}$ & $\mathrm{Cr}$ & Mo & v & $S \max$ & $\mathrm{P} \max$ \\
\hline 14MoV6-3 & $0.10-0.18$ & $\begin{array}{l}0.15- \\
0.40\end{array}$ & $0.45-0.70$ & $0.50-0.75$ & $\begin{array}{c}0.40- \\
0.0\end{array}$ & $\begin{array}{l}0.22- \\
0.35\end{array}$ & 0.040 & 0.0405 \\
\hline
\end{tabular}

We performed tensile tests with subsequent determination of the curve of actual stress-actual strain, SPT tests for all three grades.

The SPT method belongs to advanced testing methods that are developed on the long term basis in the company MATERIÁLOVÝ A METALURGICKÝ VÝZKUM, s.r.o. This method makes it possible to obtain a number of mechanical properties with the use of the relatively small size of the test specimen. This method is used mainly for evaluation of the current state of mechanical properties of the components exploited in 
classical power engineering. The main advantage of the SPT method lies in the low volume of the experimental material and also in the fact that it is possible to obtain a number of properties from the conducted SPT tests. The SPT principle is illustrated in Figure 3. The test corpuscle is a disc with a diameter of $8 \mathrm{~mm}$ and a thickness of $0.5 \mathrm{~mm}$, which is penetrated by a hemispherical puncher with a diameter of $2 \mathrm{~mm}$ until the failure. Record of the test result is shown in Figure 4, from which it is then possible, on the basis of correlation relationships, to obtain the required values of mechanical properties [4].
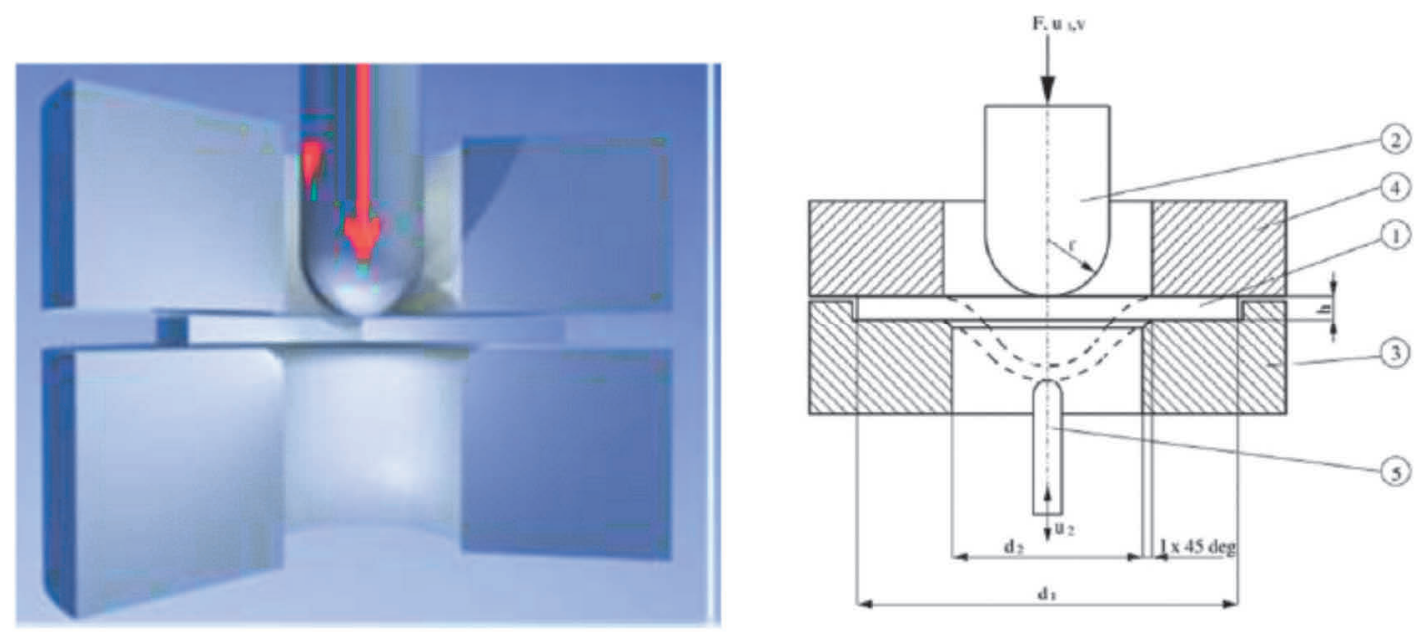

Figure 3 Principle of the small punch test (SPT)

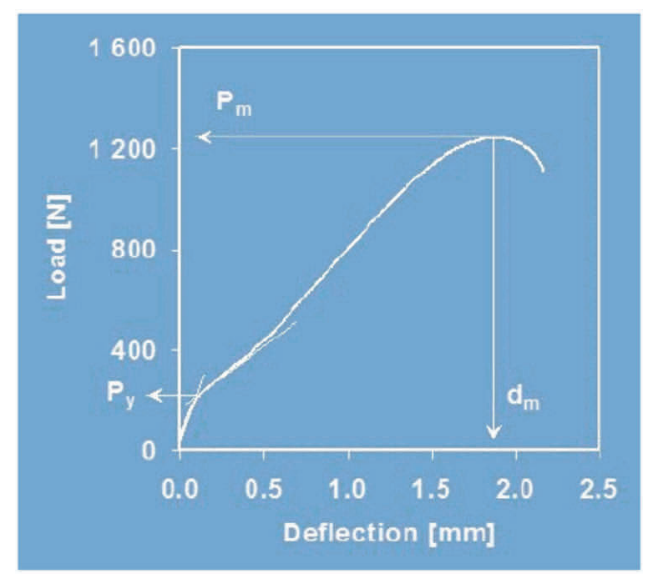

Figure 4 Typical SPT record

\section{RESULTS}

All investigated materials were tested within the algorithm for evaluation of the steel material properties based on the Small Punch Test and neural network. The given 100 experimental pairs were gradually used for the training and testing of the neural network. There were always 99 pairs for the training of the network and one for the testing. The pair changes in the way, that each pair was once a testing and 99 times a training one. The neural network provides a prediction of the material values (output) for the testing input (force vs displacement). Since these values are known (from the experiment), but not used for the training, the quality of such prediction can be assessed just with the comparison of the predicted and real values (output - E, $R_{p 02}$ and $R_{m}$ ). The error was calculated in absolute (MPa) and relative (\%) values and the mean error was evaluated. Obtained results are compared with results based on all data points for all tested materials together. Results are given in the Table 4 and Table 5. 
Table 4 Result of numerical simulation of mechanical properties using neural network for 100 data points

\begin{tabular}{|c|c|c|c|c|}
\hline Material & Quantity & $\begin{array}{c}\text { Mean Absolute } \\
\text { Error } \\
\text { (MPa) }\end{array}$ & $\begin{array}{l}\text { Max. Absolute Error } \\
\text { (MPa) }\end{array}$ & $\begin{array}{c}\text { Mean Relative Error } \\
(\%)\end{array}$ \\
\hline \multirow{3}{*}{ 10GN2MFA } & $E$ & 18915 & 46772 & 9.24 \\
\hline & $\mathrm{R}_{\mathrm{p} 0,2}$ & 23.03 & 120.14 & 4.28 \\
\hline & $\mathrm{R}_{\mathrm{m}}$ & 18.79 & 92.55 & 2.94 \\
\hline \multirow{3}{*}{ 08Ch18N10T } & $E$ & 19540 & 59676 & 11.94 \\
\hline & $\mathrm{R}_{\mathrm{p} 0,2}$ & 18.11 & 82.13 & 5.74 \\
\hline & $\mathrm{R}_{\mathrm{m}}$ & 9.57 & 42.36 & 1.58 \\
\hline \multirow{3}{*}{ 14MoV6-3 } & $E$ & 31977 & 76028 & 16.88 \\
\hline & $\mathrm{R}_{\mathrm{p} 0,2}$ & 20.48 & 79.70 & 8.22 \\
\hline & $\mathrm{R}_{\mathrm{m}}$ & 12.98 & 63.81 & 2.83 \\
\hline
\end{tabular}

Table 5 Effect of data points on numerical simulation results

\begin{tabular}{|c|c|c|c|}
\hline \multirow{2}{*}{ Material } & Quantity & $\begin{array}{c}\text { Mean Relative Error } \\
100 \text { specimens } \\
\text { (\%) }\end{array}$ & $\begin{array}{c}\text { Mean Relative Error } \\
\mathbf{3 0 0} \text { specimens } \\
\text { (\%) }\end{array}$ \\
\hline \multirow{3}{*}{ 10GN2MFA } & $\mathrm{E}$ & 9.24 & 8.70 \\
\cline { 2 - 4 } & $\mathrm{R}_{\mathrm{p} 0,2}$ & 4.28 & 4.02 \\
\cline { 2 - 4 } & $\mathrm{R}_{\mathrm{m}}$ & 2.94 & 3.04 \\
\hline \multirow{3}{*}{ 08Ch18N10T } & $\mathrm{E}$ & 11.94 & 10.3 \\
\cline { 2 - 4 } & $\mathrm{R}_{\mathrm{p} 0,2}$ & 5.74 & 1.08 \\
\hline & $\mathrm{R}_{\mathrm{m}}$ & 1.58 & 17.41 \\
\hline \multirow{2}{*}{ 14MoV6-3 } & $\mathrm{E}$ & 16.88 & 8.17 \\
\cline { 2 - 4 } & $\mathrm{R}_{\mathrm{p} 0,2}$ & 8.22 & 2.83 \\
\hline
\end{tabular}

It follows from the obtained results summarized in Table $\mathbf{4}$ and Table $\mathbf{5}$, that the simulations here have good agreement with the experimental results. In our previous work started 3 year ago [1] only limited number of data set, that do not exceed 18 results was available. Such number of data set was found to be not acceptable as the scatter was too high. After improving NN methodology and increased number of experimental data, the good agreement was found.

Table 5 clearly shows positive effect of enlarged data file as the drop in mean relative error was identified in most cases. Relative error for tensile strength is very low and varies between 1 and $3 \%$. on the other hand for yield strength mean error increases up to $8 \%$ for 14MoV6-3 grade steel, such behavior is connected with strong yield strength compared to two others materials where $0.2 \%$ proof strength was observed.

Achievement of consistent results when estimating material characteristics using neural networks would probably require a much bigger number of training samples. This is compliant with the literature [8], which states the need for at least several hundreds or thousands of pairs, for the proper functioning of the neural network. Consequently, this method would require a database of the experiments for each material used in the real world. One could not assume that building one wide database for any kind of material will bring much 
more reasonable results. Further work is continuing with building database for P91 and P92 grade steels used in power industry application with USC parameters $[9,10]$.

\section{CONCLUSION}

Based on the experimental work as well as numerical simulation following conclusions the following can be postulated. Neural network is a potent method capable evaluate of material properties based only on the SPT record. Precision of such prediction strongly depends on the number of data points using for calculation as well as on the structure of neural network. Nevertheless, good agreement with experimental results can be already obtained using data set with approx. 300 data points. In such case mean error for tensile strength varies between 1-3\% and for yield stress between 4 and $8 \%$ it seems to be quite good agreement. Further work is focused on the continuation of the experimental tests and enlarging recent database as well as on building the material database using new materials like P91, P92.

\section{ACKNOWLEDGEMENTS}

\section{This work was financially supported with the TAČR project 'TE01020068 Centre of Research and Experimental Development of Reliable Power Engineering' funded by the Czech Technology Agency.}

\section{REFERENCES}

[1] KANDER, L., and ŠPIČKA, J. Utilization of Neural Networks for Evaluation of Material Properties of Structural Steels based on SPT Results. Metallurgical Journal. 2017. vol. 4, pp. 24-29.

[2] CATHERINE, C. S., MESSIER, J., POUSSARD, C., ROSINSKI, S. and FOULDS, J. Small punch test: EPRI-CEA finite element simulation benchmark and inverse method for the estimation of elastic plastic behaviour. In: Small Specimen Test Techniques 4. ASTM International, 2002, pp. 350-370.GODWIN, P. Library 2.0: a retrospective. In: GODWIN, Peter and PARKER Jo, eds. Information literacy beyond library 2.0. London: Facet, 2012, Part 1: Recent developments in information literacy and library, chapter 1, pp. 3-18.

[3] ALTSTADT, E., SIMONOVSKI, I., BRUCHHAUSEN M., HOLMSTRÖM S. and LACALLE R. On the estimation of ultimate tensile stress from small punch testing, Int. J. Mech. Sci. 2018. vol. 136, pp. 85-93.

[4] EN 15267, CD of standard. Small Punch Test Method for Metallic Materials. 2018 (will be published).

[5] C CSN EN ISO 9862-1 Metallic materials - Tensile testing - Part 1: Method of test at room temperature, 2017, UNMZ, Praha, 2017.

[6] ASTM E8/E8M-16a, Standard Test Method for Tension Testing of Metallic Materials, ASTM International, West Conshohocken, PA, 2016.

[7] ŠPIČKA, J., KANDER, L. and ČÍŽEK, P. Neural Network Utilization for Evaluation of the Steel Material Properties. In $5^{\text {th }}$ International Small Sample Test Techniques Conference. Swansea: PEMS, 2018, pp. 135-140.

[8] ABENDROTH, M. and MEINHARD, K. Determination of ductile material properties by means of the small punch test and neural networks. Advanced Engineering Materials. 2004. vol. 6, no. 7, pp. 536-540.

[9] BRUCHHAUSEN, M., HOLMSTRÖM, S., LAPETITE, J.-M. and RIPPLINGER S. On the determination of the ductile to brittle transition temperature from small punch tests on Grade 91 ferritic-martensitic steel. Int. J. Press. Vessels Pip. 2017. vol. 155, pp. 27-34.

[10] JEFFS, S.P. and LANCASTER, R.J. Small punch tensile/fracture test data for P92 material at $23.5^{\circ} \mathrm{C}$ and a displacement rate of 00833 mm/s, version 1.2, European Commission JRC, [Dataset], 2017. 